\title{
Dieulafoy lezyonu'nun başarılı endoskopik tedavisi
}

\author{
Successful endoscopic treatment of Dieulafoy's lesion
}

Hüseyin ALKIM

Bakırköy Dr. Sadi Konuk Eğitim ve Araștırma Hastanesi, Gastroenteroloji Kliniği, Istanbul

Dieulafoy lezyonu, bütün gastrointestinal sistemde görülebilse de \%80'i proksimal midede bulunan seyrek görülen masif bir kanama sebebidir. Herhangi bir ülser olmadan, lümene protrüde olan veya aktif kanayan damar șeklinde görülür. Endoskopik olarak saptanması ve tedavisi güçtür. Burada masif kanama nedeniyle acil total gastrektomi planlanan 74 yașinda bir erkek hastada mide proksimalindeki Dieulafoy lezyonunun saptanmasını ve başarılı tedavisini sunuyoruz.

Anahtar kelimeler: Dieulafoy lezyonu, kanama, endoskopik tedavi

\section{GİISS}

Akut varis dışı üst gastrointestinal kanamaların en sık sebebi peptik ülser hastalığıdır. Endoskopik ve diğer tanı ve tedavi yöntemlerindeki gelişmelere rağmen mortalite oranı halen \%7-10'dur. Üst gastrointestinal kanama ile başvuranların \%5-10 kadarında, objektif kanama bulgusuna rağmen kanamaya neden olan lezyon saptanamayabilir. Kanama odağ1 anatomik olarak ulaşılamaz olabilir ya da küçük, silik bir lezyon olabilir. Nedeni saptanamayan bu kanamalara 'obscure' gastrointestinal kanama denir. 'Obscure' kanamalar akut (açık) ya da gizli kanama biçiminde olabilir. Akut masif kanamaya neden olup saptanması zor olan 'obscure' kanamaların nedenlerinden bir tanesi Dieulafoy lezyonudur $(1,2)$.

Normal koşullarda arterler gittikçe incelerek hedef organlarında kapillerlere dönüşerek sonlanırlar. Dieulafoy lezyonunda histolojik olarak normal olan arterin çapı giderek incelmez, anormal olarak geniş (1-3 mm) ve tortiyoze biçimde submokozada bulunur. Bu nedenle 'kalibre persistan arter' olarak da adlandırılmaktadır. Bu arter 2-5 mm'lik küçük bir mukozal defektten protrüde olur ve kanar. Etyolojisi kesin olarak bilinmemektedir, konjenital olabileceği, yaşlanmakla da gelişebileceği düşünülmektedir. Tam olarak insidansı bilinmemekle birlikte akut üst gastrointestinal kanamaların \%1-2'sinden sorumlu olduğu kabul edilmektedir. Tüm yaş gruplarında görülebilir, ancak 60 yaş üstü erkeklerde daha sık görülür. Seyrek görülse de akut, masif ve fatal olabilen Dieulafoy lezyonu kanamaları, gastrointestinal kanamaların ayırıcı tanısında akılda tutulup endoskopi sırasında özellikle aranmazsa kolaylıkla atlanabilir (1-5).
Dieulafoy's lesion is a rare cause of massive bleeding, which may be seen in any part of the gastrointestinal tract, but $80 \%$ of the lesions are reported in the proximal stomach. It is seen as a protruding or actively bleeding vessel without any ulcer. Endoscopic detection and treatment is difficult. Here, we present successful detection and treatment of a Dieulafoy's lesion located in the proximal stomach in a 74-year-old male patient, for whom urgent total gastrectomy was planned for the massive bleeding

Key words: Dieulafoy's lesion, bleeding, endoscopic treatment

\section{OLGU}

Yetmiş dört yaşında erkek hastaya, bir gün önce gelişen hematemez ve melena ile başvurduğu özel bir hastanede toplam 8 ünite kan transfüzyonu yapılmış. Yapılan endoskopide diffüz gastrik mukozal kanama tanısı konarak hastaya total gastrektomi önerilmiş. Hasta ameliyatı reddederek hastanemize başvurduğunda hipotansif ve taşikardikdi. Uykuya eğilimi vardı. Barsak sesleri çok aktif olup, makattan devamlı taze kan ve pıhtı gelmekteydi. Özgeçmişinde atherosklerotik kalp hastalığı ve ürolitiazis dışında özellik yoktu. Laboratuvar bulguları şöyleydi: HGB: 8.1 gr/dl, HCT: \%25, PLT: 98000/ul, WBC: 10000/ $\mu 1$, albumin: 2.7 gr/dl, BUN: 51 mg/dl . Acil olarak yapılan gastroskopide, mide taze kırmızı kan ile doluydu, küçük kurvatura tarafinda, angulusun hemen üzerinde, etrafinda ülser bulunmayan aktif kanamalı damar görüldü (Resim 1). Damarın önce etrafina sonra ortasına adrenalin (1:10000) injeksiyonunu takiben bipolar prob ile damar yakılarak kanama durduruldu (Resim 2). Tedavi sonrası hastanın hemodinamisinde hızlı bir düzelme oldu. Hastanemize başvurduktan sonra toplam 4 ünite daha eritrosit süspansiyonu transfüzyonu yapılan hastanın endoskopik tedavi sonrası hemodinamisi hızla düzeldi ve HCT \%3l'e çıktı. Takibinde kanama tekrarlamadi.

\section{TARTIŞMA}

Dieulafoy lezyonu seyrek görülen, tanı konulması zor, akut abondan ya da tekrarlayan gastrointestinal kanama nedeni olabilen submukozal kalibre persistan arterdir. Tüm gastrointestinal traktta bulunabilse de en sik midede görülür. Mide- 


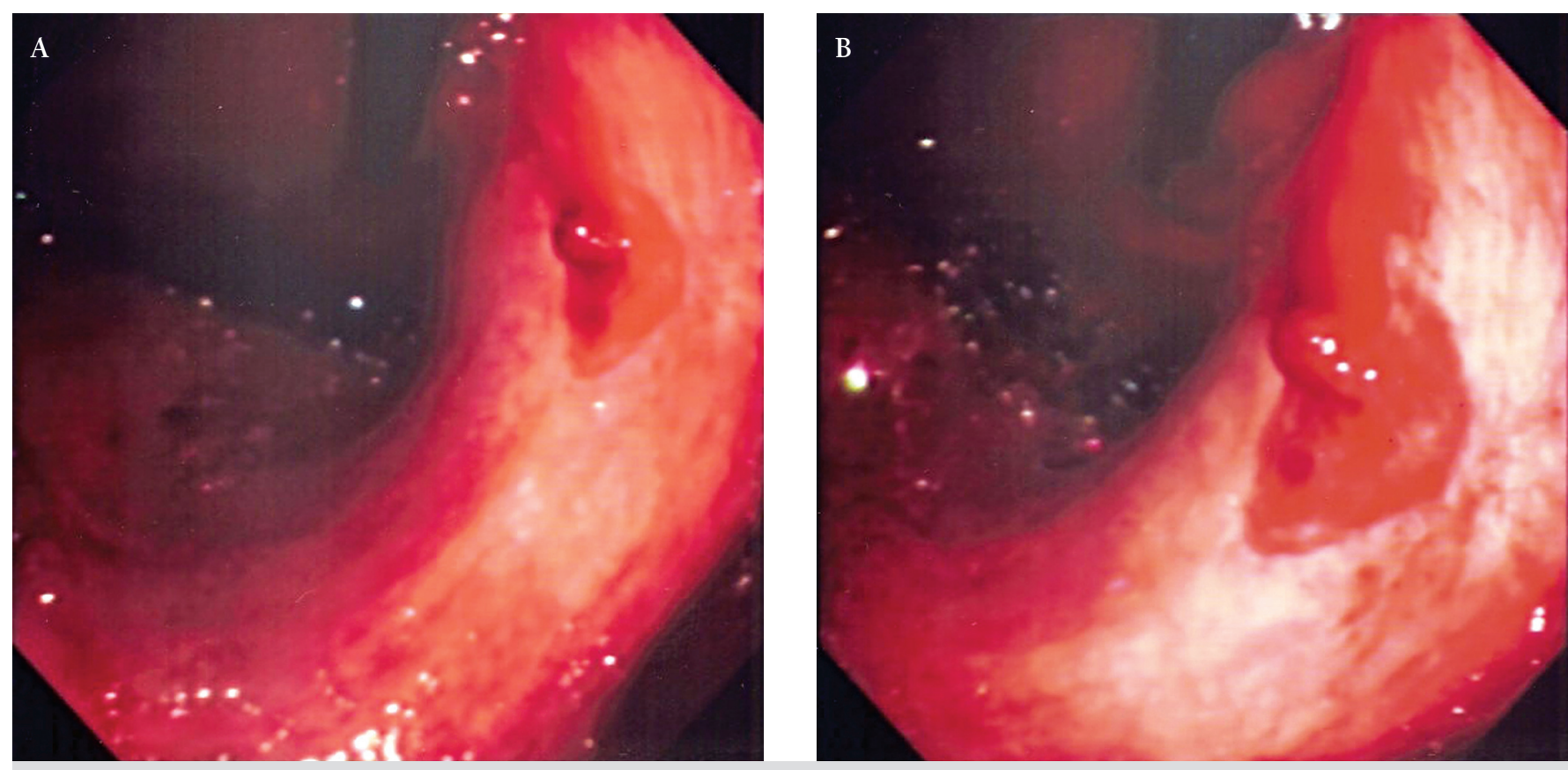

Resim 1 A ve B. Mide proksimalinde, küçük kurvatura üzerinde aktif kanayan Dieulafoy lezyonu.
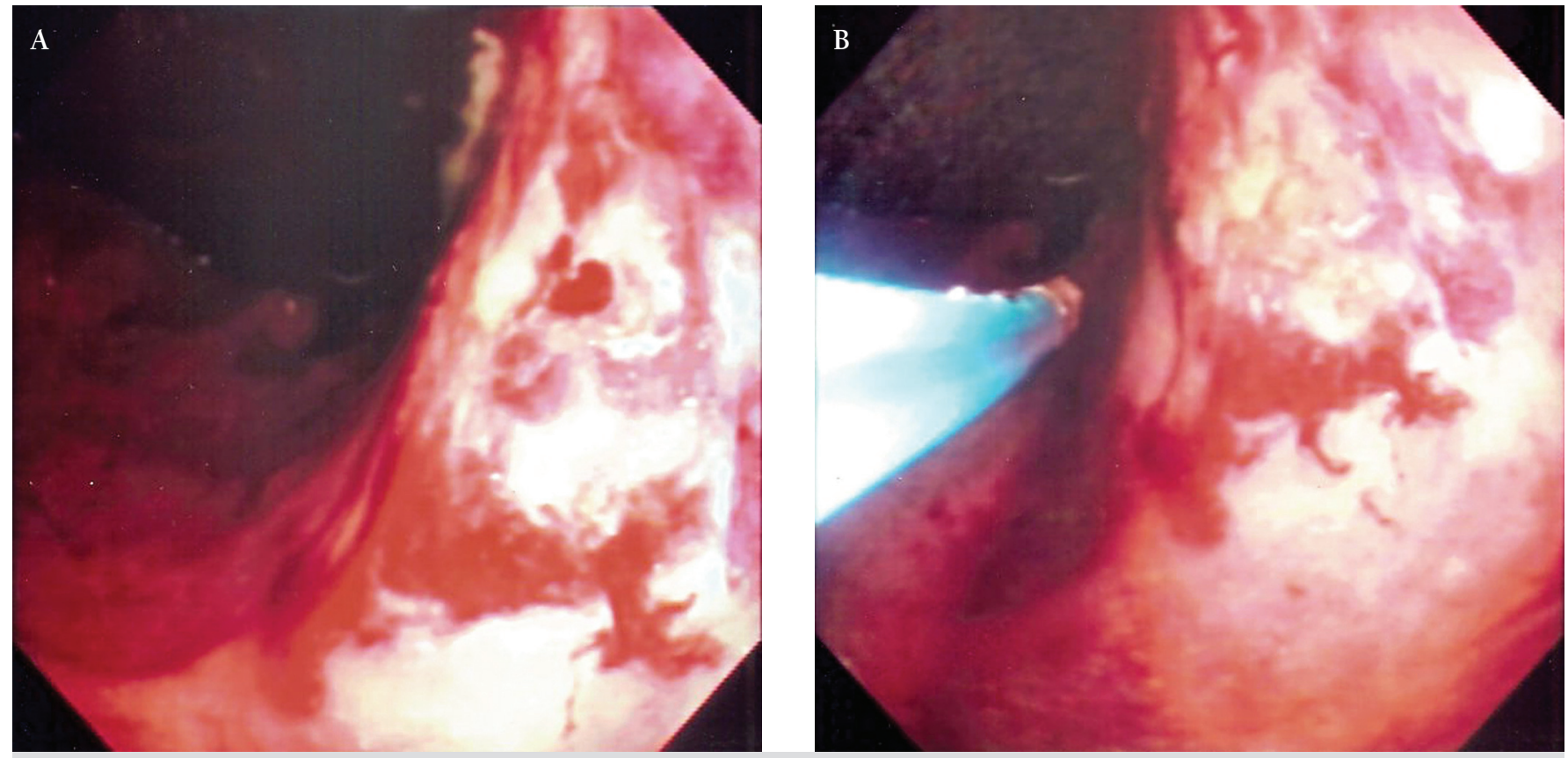

Resim 2. A. Adrenalin ile injeksiyon yapıldıktan sonra kanama durdurulmuş, ortada damar görünüyor. B. Bipolar prob ile damarın yakılması.

deki lezyonların \%80-95'inde kanama odağı gastroözofageal bileşkeye komşu 6 cm'lik mesafede küçük kurvaturada saptanır. Dieulafoy lezyonlarının yaklaşık üçte biri mide dışında bulunur, en sik duodenumda daha sonra da kolonda görüldügü bildirilmiştir. Çalışmalarda \%71 midede, \%15 duodenumda, \%8 özofagusda, \%4 kolorektal bölgede, \%1 ince barsakta, \% 1 gastrik anastomozlarda saptanmıştır. Gastrointestinal trakt dışında bronşlarda tanımlanan olgular da vardır
$(2,3)$. Bizim olgumuzda lezyon en çok görüldüğü yer olan proksimal midede küçük kurvatura üzerindeydi.

Dieulafoy lezyonu görülen hastalar genellikle yaşl, çoklu yandaş hastalığı olan sıklıkla nonsteroid antiinflamatuvar, aspirin ve varfarin kullananan hastalardır (2). Bizim hastamız da 75 yaşında bir kalp hastasıydı.

Dieulafoy lezyonunun tanısinda gastrointestinal endoskopi 
ilk yapılacak tetkikdir. Başlangıç endoskopisinde tanı koyma oranı \%70 civarındadır. Midenin kanla dolu olması, kanamanın intermitan olabilmesi nedeniyle endoskopi sırasında durmuş olması ve damar etrafında ülser benzeri bir lezyon olmaması nedeniyle sıklıkla gözden kaçabilmekte ve tanı konulamamaktadır. Wright ve ark. (4) tanı koyabilmek için intravenöz heparin bolusu ile kanamayı provoke etmişlerdir. Dieulafoy lezyonunda tanı konulamaması nedeniyle endoskopi tekrarları gerekebilir. Bizim vakamızda da başka bir merkezde yapılan endoskopide de tanı konulamamış ve hastaya toplam 8 ünite kan transfüzyonu yapıldığı için diffüz mukozal kanama ön tanısıyla total gastrektomi önerilmişti. Hastanemizde başvurduğunda yaptığımız endoskopide ise lezyonu saptayarak tedavisini başarılı bir şekilde yaptık.

Dieulafoy lezyonundan şüphelendikten sonra endoskopide tanı için kullanılabilecek kriterler tanımlanmıştır $(1,2)$. Bunlar:

1. 3 mm'den küçük mukozal defektten ya da normal mukozadan aktif arterial fişkırır tarzda ya da mikropulzatil kanama,

2. Küçük mukozal defektten ya da normal mukozadan görünen damar,

3. Küçük mukozal defekt ya da normal mukozaya yapışık taze pihtı görülmesi olarak sıralanabilir.

Lezyonun tabanında ülser olmaması, sadece mukozal defekt olması önemlidir. Endosonografi ile submukozal genişlemiş damarlar gösterilebilir. Tanı konulamayan olgularda endosonografi veya anjiografi tanıya yardımcı olabilir. Mide duodenum dışındaki lezyonlarda yerine göre kolonoskopi, enteroskopi, kapsül endoskopi kullanılabilir. Kanama odağı saptanamayan olgularda eritrosit sintigrafisi lokalizasyon konusunda yararlı olabilir.

Dieulafoy lezyonunun tedavisi konusunda tam bir fikir birliği yoktur. Lezyonun yerine, ulaşılabilirliğine, deneyime göre

\section{KAYNAKLAR}

1. Patel P, Tobi M. Dieulafoy-like lesion bleeding: In the loop. Gastroenterol Hepatol 2011;7:271-4

2. Baxter M, Aly EH. Dieulafoy's lesion: current trends in diagnosis and management. Ann R Surg Eng 2010;92:548-54.

3. Alshumrani G, Almuaikeel M. Angiographic findings and endovascular embolization in Dieulafoy disease: a case report and literature review. Diagn Interv Radiol 2006;12:151-4.

4. Wright CA, Peterswsen, Bridges CM, Alexander JA. Heparin provocation for identification and treatment of a gastric Dieulafoy's lesion. Gastrointest Endosc 2004;59:728-30.

5. Chung IK, Kim EJ, Lee MS, et al. Bleeding Dieulafoy's lesions and the choice of endoscopic method: comparing the haemostatic efficacy of mechanical and injection methods. Gastrointest Endosc 2000;52:721-4. tedavi yöntemi seçilmektedir. Endoskopik yöntemlerle \%90 olguda kanama kontrol altına alınmaktadır. Injeksiyon tedavisi (adrenalin, saf alkol, skleroterapi), termal yöntemler (heater prob, bipolar prob, argon plazma koagülasyon) veya mekanik yöntemler (bandlama, hemoklip) ile başarılı endoskopik tedavi yapilabilmektedir. Tüm endoskopik tedavi yöntemlerinin avantajları ve dezavantajları vardır. Chung ve ark. (5) 24 hastada mekanik yöntemler ile injeksiyon tedavisini karşılaştırdıkları çalışmalarında mekanik yöntemleri başlangıç hemostazı, kanama tekrarı ve cerrahi gereksinimi yönünden daha üstün buldular. Bir olguda midedeki Dieulafoy lezyonuna band uygulanmış, aktif kanama durdurulmuş, ancak 10 gün sonra acil laparotomi gereken nüks kanama olmuştur (6). Avlan ve ark. (7) 3 yaşındaki çocukta Dieulafoy lezyonunu adrenalin injeksiyonu ile tedavi etmişlerdir. Sone ve ark. (8) Dieulafoy lezyonu saptanan 61 hastanın 48'ine hemoklip, geri kalanlara injeksiyon tedavisi uygulayarak hepsinde kanamayı durdurmuşlar. Tekrar kanayan tek bir hastayı da ikinci seans endoskopik tedaviyle tedavi etmişler, cerrahiye verilen hasta olmamıştır.

Endoskopik tedavi yöntemlerinin kombinasyonunun monoterapiden daha başarılı olabileceği düşünülmektedir. Eddi ve ark. (9) Billroth 2 gastrojejunostomili hastada afferent luptaki Dieulafoy lezyonuna önce adrenalin enjeksiyonu yapıp üstüne 3 adet hemoklip atarak kanamayı durdurmuşlardır. Biz de vakamızın kanamasını adrenalin injeksiyonu ile durdurduktan sonra bipolar kontakt prob uygulayarak damarı tromboze ettik. Bu şekilde tekrar kanama riski azaltılabilmektedir.

Endoskopik yöntemlerin gelişmesi Dieulafoy lezyonunun saptanmasını artırmış, mortaliteyi \%80'den \%8,6'ya düşürmüştür (2). Alternatif tedaviler olan anjiografik embolizasyon ve cerrahiye olan gereksinimi azaltmıştır. Eskiden mutlaka cerrahi müdahale gerektiren mortalitesi yüksek bir kanama kaynağı olan Dieulafoy lezyonu, artık endoskopik olarak saptanıp başarılı şekilde tedavi edilebilmektedir.

6. Rahbour G, Ulah MR, Siddiqui, et al. Dieulafoy lesion endoscopically rubber banded, with further severe haematemesis requiring emergency laparotomy- case report. Int J Surg Case Rep 2011:2:154-6.

7. Avlan D, Nayci, A, Altintas E, et al. An unusual cause for massive upper gastrointestinal bleeding in children: Dieulafoy's lesion. Pediatr Surg Int 2005;21:417-8.

8. Sone Y, Kumada T, Toyoda H, et al. Endoscopic management and follow up of Dieulafoy lesion in the upper gastrointestinal tract. Endoscopy 2005;37:449-53.

9. Eddi R, Shah N, Depasquale JR. Gastrointestinal bleeding due to a Dieulafoy lesion in the afferent limb of a Billroth 11 reconstruction. Gastroenterol Hepatol 2011;7:268-71. 